\title{
Research on the wet shot blasting technology of strip steel surface topography and finite element simulation
}

\author{
Zhi Gao ${ }^{a}$, Yinjian $\mathrm{Bu}^{\mathrm{b}}$ \\ School of Mechanical and Power Engineering, East China University of Science and Technology, \\ Shanghai 200237, China \\ agaozhi@ecust.edu.cn, bbuyinjian@126.com
}

Keywords: Shot blasting process, ANSYS/LS-DYNA, dynamics simulation, wet shot blasting.

\begin{abstract}
In order to solve the problem of pollution in the strip steel pickling process, we propose a new process of wet shot blasting, adding water system in the conventional shot blasting equipment. Through the finite element software ANSYS/LS-DYNA, we conduct the dynamic simulation of dry and wet shot blasting and analyze the relationship of shot blasting parameters on von misses stress, effective strains of strip steel. The verification by this experiment is that wet shot blasting reduces the stress effectively by the time ensuring the strain, which guarantees the consistency of the properties of different areas of strip steel surface.
\end{abstract}

\section{Introduction}

After hot rolling, strip steel surface will be oxidized and generate oxide skin. Pickling process is widely used in removing oxide layer. However, pickling process [1] is a great threat not only to employee's heath, but also to the surrounding environment. Nowadays, environmental protection is increasingly valued, we need to explore a new process urgently to replace pickling process.

Shot blasting technology [2, 3] has been widely used in the surface treatment of strip steel. However, conventional shot blasting equipment has some problems, such as non-ideal separation and collection of dust and projectile, surface scratches. Therefore, it's rarely used in strip steel production line. In the article, we explore a new shot blasting technology instead of pickling process. In order to solve above problems, we add water system to the shot blasting equipment. In order to prove the feasibility of new process, we conduct the dynamic simulation of dry and wet shot blasting through the software ANSYS/LS-DYNA [4-6]. We also make the experiment to verify the effect of wet shot blasting technology.

\section{Finite element model of shot blasting collision process}

In the finite element analysis, projectile and strip steel adopt lagrangian mesh model, water adopts ALE, using solid 164 element. The constitutive relation of the projectile and strip steel adopt bilinear isotropic hardening model, water adopts null empty material model, and its relationship between pressure and volume adopts greisen state equation.

$$
P=\frac{\rho_{0} C^{2} \mu\left[1+\left(1-\frac{\gamma_{0}}{2}\right) \mu-\frac{a}{2} \mu^{2}\right]}{\left[1-\left(S_{1}-1\right) \mu-S_{2} \frac{\mu^{2}}{\mu+1}-S_{3} \frac{\mu^{3}}{(\mu+1)^{2}}\right]^{2}}+\left(\gamma_{0}+a \mu\right) E
$$

The projectile goes through the water layer at a high speed (assuming VC) into the steel plate. Shot blasting strengthening diagram is shown in figure 1 , steel surface stress distribution is shown in figure 2. $R_{p}$ represents the radius of projectile, $r_{e}$ represents the radius of pit, $\sigma_{\max }$ represents maximum stress of contact area, and oav represents the average stress of contact area.

According to the Hertz contact theory [7, 8], we can get the maximum force of contact area.

$$
F_{\max }=\left(\frac{20 \pi}{3} \rho_{1}\right)^{3 / 5} \mathrm{r}_{\mathrm{p}}^{2}\left(6\left(\frac{1-v_{1}^{2}}{\mathrm{E}_{1}}+\frac{1-v_{2}^{2}}{\mathrm{E}_{2}}\right)\right)^{-2 / 5} \mathrm{v}_{\mathrm{p}}^{6 / 5}
$$


In the formula, $\rho_{1}$ - the density of projectile, $v_{1}$ - poisson's ratio of projectile, $v_{2}$ - poisson's ratio of strip steel, $E_{1}, E_{2}$-the elastic modulus of projectile and strip steel.

$$
\mathrm{r}_{\mathrm{e}}=\left(\frac{3}{4} F_{\max } \mathrm{r}_{\mathrm{p}}\left(\frac{1-v_{1}^{2}}{\mathrm{E}_{1}}+\frac{1-v_{2}^{2}}{\mathrm{E}_{2}}\right)\right)^{1 / 3}
$$

Then, we can deduce the average stress of the contact area $\left(\sigma_{\mathrm{av}}\right)$.

$$
\sigma_{\mathrm{av}}=\frac{F_{\max }}{\pi \mathrm{r}_{\mathrm{e}}^{2}}=\frac{2}{3}\left[\frac{40}{\pi^{4}} \rho_{1}\left(\frac{1-v_{1}^{2}}{\mathrm{E}_{1}}+\frac{1-v_{2}^{2}}{\mathrm{E}_{2}}\right)^{-4}\right]^{1 / 5} \mathrm{v}_{\mathrm{p}}^{2 / 5}
$$
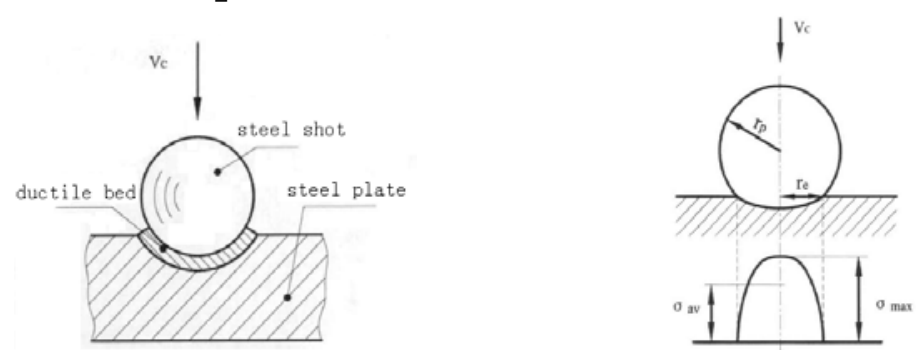

Fig.1 Schematic diagram of shot blasting Fig.2 Diagram of stress and deformation

We conduct the simulation analysis with different parameters, such as different diameter $(0.2 \mathrm{~mm}$, $0.3 \mathrm{~mm}, 0.4 \mathrm{~mm}, 0.6 \mathrm{~mm}, 1.0 \mathrm{~mm}, 1.4 \mathrm{~mm})$, different velocity $(40 \mathrm{~m} / \mathrm{s}, 60 \mathrm{~m} / \mathrm{s}, 80 \mathrm{~m} / \mathrm{s}, 100 \mathrm{~m} / \mathrm{s})$, different incident angle $\left(45^{\circ}, 60^{\circ}, 75^{\circ}, 90^{\circ}\right)$. Wet shot blasting means the projectile hits water and strip steel, and dry shot blasting means the projectile hits strip steel directly. Assuming that the projectile is on the critical contact surface, there is only a layer of water on the strip steel surface in the wet shot blasting. The parameters of projectile and strip steel are shown in table 1 . Collision model belongs to the plane of symmetry, we adopt $1 / 2$ solid modeling in order to reduce the amount of calculation. The size of strip steel is $120 \mathrm{~mm} \times 120 \mathrm{~mm} \times 3 \mathrm{~mm}$, the thickness of water is $1 \mathrm{~mm}$.

Table 1 Parameters of model material

\begin{tabular}{cccccc}
\hline & DENS/ $/ \mathrm{cm}^{3}$ & EX/ GPa & NUXY & Tangent Modulus/ GPa & Yield Stress/ MPa \\
\hline Steel shot & 7.4 & 200 & 0.3 & 76.923 & 540 \\
Steel plate & 7.8 & 210 & 0.269 & 82.742 & 355 \\
\hline
\end{tabular}

\section{Shot blasting simulation results based on ANSYS/LS-DYNA}

According to the established model, we conduct the impact dynamics analysis. Wet shot blasting collision diagram is shown in figure 3 , there is no water layer in dry shot blasting.

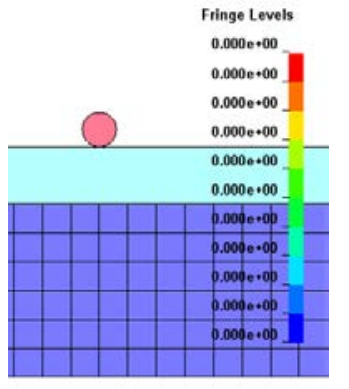

(a) before collision

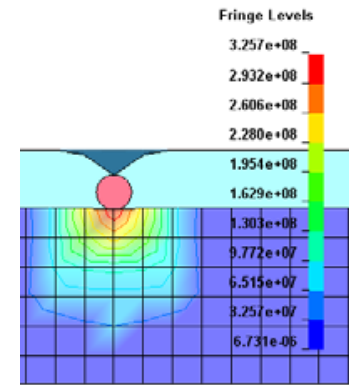

(b) under collision

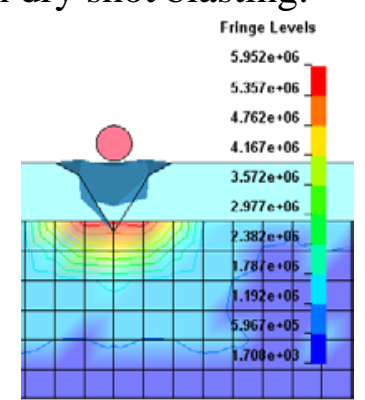

(c) after collision

Fig.3 Schematic diagram of wet shot blasting

The dynamics simulation results of dry and wet shot blasting are as follows:

Dry shot blasting condition 1: The projectile with $0.6 \mathrm{~mm}$ diameter and $90^{\circ}$ incident angle hits the strip steel at different speeds $(40 \mathrm{~m} / \mathrm{s}, 60 \mathrm{~m} / \mathrm{s}, 80 \mathrm{~m} / \mathrm{s}, 100 \mathrm{~m} / \mathrm{s})$. Von mises stress is shown in figure 4 , effective strain is shown in figure 5 . Von mises stress increases with the increase of velocity, with a greatly improvement when the speed reaches at $80 \mathrm{~m} / \mathrm{s} \sim 100 \mathrm{~m} / \mathrm{s}$. Effective strain increases with the increase of the velocity in a linear relationship.

Dry shot blasting condition 2: The projectile with $0.6 \mathrm{~mm}$ diameter and $80 \mathrm{~m} / \mathrm{s}$ speed hits the strip steel at different incident angle $\left(45^{\circ}, 60^{\circ}, 75^{\circ}, 90^{\circ}\right)$. Von mises stress is shown in figure 6 , effective 
strain is shown in figure 7. Von mises stress and effective strain increases with the increase of the incident angle, with a smaller changes, which means that the incident angle has a less effect.

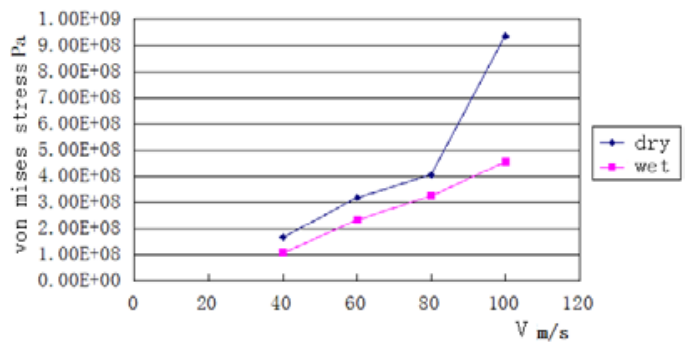

Fig.4 Diagram of von mises stress-velocity

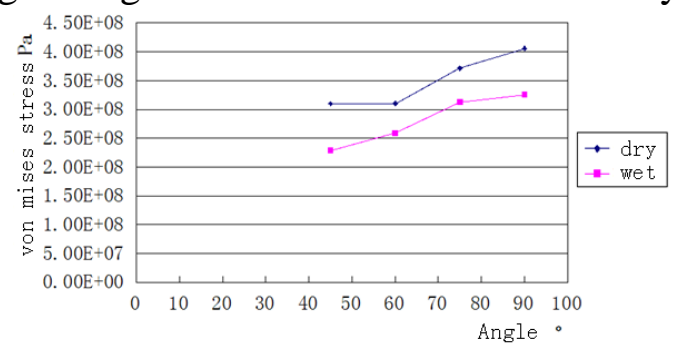

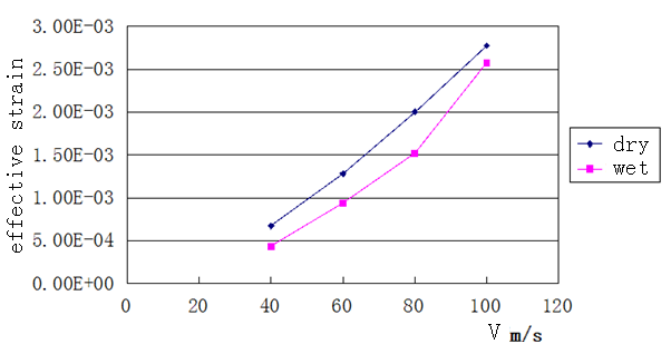

Fig.5 Diagram of effective strain-velocity

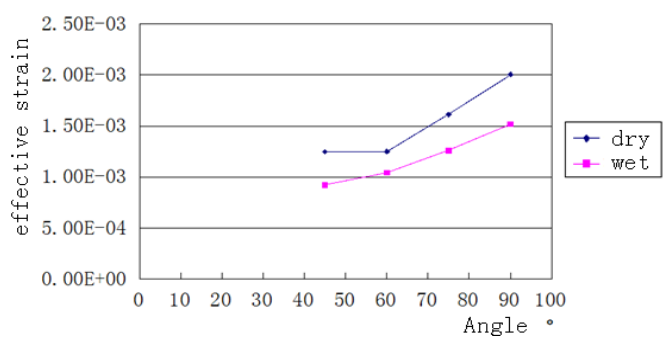

Fig.6 Diagram of von mises stress-incident angle Fig.7 Diagram of effective strain-incident angle

Dry shot blasting condition 3: The projectile with $80 \mathrm{~m} / \mathrm{s}$ speed, $90^{\circ}$ incident angle and different diameter $(0.2 \mathrm{~mm}, 0.3 \mathrm{~mm}, 0.4 \mathrm{~mm}, 0.6 \mathrm{~mm}, 1.0 \mathrm{~mm}, 1.4 \mathrm{~mm})$ hits the strip steel. Von mises stress is shown in figure 8, effective strain is shown in figure 9 . Von mises stress increases with the increase of diameters in a linear relationship. Effective strain increases with the increase of diameters. We can find that both are influenced greatly by diameters.

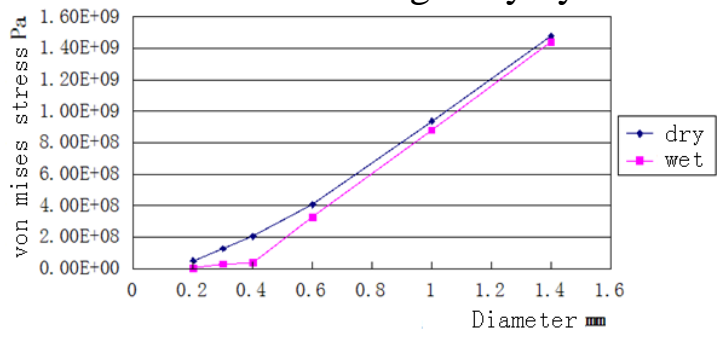

Fig.8 Diagram of von mises stress-diameter

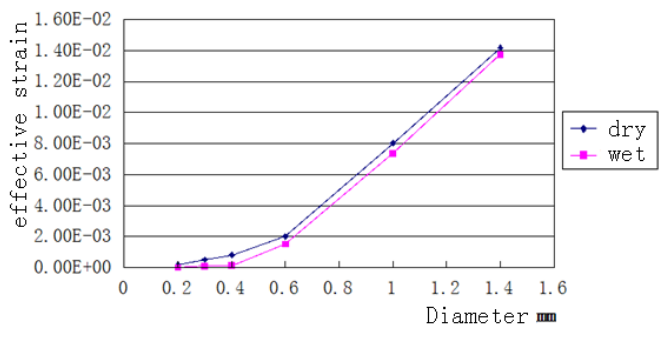

Fig.9 Diagram of effective strain-diameter

The relative results are shown in figure 5 figure 10 . Through analysis and comparison, we can find that the effects are basically the same. However, wet shot blasting generally reduces von mises stress and effective strain. Von mises stress is not improved greatly when the speed is up to $80 \mathrm{~m} / \mathrm{s} \sim$ $100 \mathrm{~m} / \mathrm{s}$, which has a same range compared with the former. When the water layer thickness is $1 \mathrm{~mm}$, diameter is less than $0.4 \mathrm{~mm}$, von mises stress and effective strain are weakened greatly, however, when diameter is larger than $0.4 \mathrm{~mm}$, the changes of von mises stress and effective strain decreases with the increase of diameter. With the change of velocity, the variation amplitude of von mises stress decreases in the wet shot blasting, the variation amplitude of effective strain changes as before. When the effective strain reduction is small, the von mises stress drop is larger. In short, wet shot blasting not only reduces von mises stress and effective strain, but also weakened the parameters which generate a greater impact on the von mises stress and effective strain.

\section{Shot blasting experiment}

We carried out the experiment with shot blasting equipment (as shown in figure 10). The diameters of projectile are respectively $0.3 \mathrm{~mm}$ and $0.2 \mathrm{~mm}$. The thickness of strip steel is $3 \mathrm{~mm}$.

The incident angle is set to $60^{\circ}$, the velocity is set to $60 \mathrm{~m} / \mathrm{s}$ according to the simulation results and experience of shot blasting parameters. Projectile impacts strip steel for $10 \mathrm{~s}$. Strip steel surface topography of magnified 100 times under scanning electron microscope is shown in figure 11.

We find that the effect of different regions is basically the same. The diameter of $0.2 \mathrm{~mm}$ projectile pit is about $60 \mu \mathrm{m}$, the diameter of $0.2 \mathrm{~mm}$ projectile pit is about $110 \mu \mathrm{m}$, which is about $1 / 3$ of the 
diameter of projectile. Through calculation, the depths of pit are respectively $4.6 \mu \mathrm{m}$ and $10.4 \mu \mathrm{m}$, which is about $28 \%$ of the diameter of projectile. The results are close to the simulation results, but $10 \% \sim 30 \%$ larger. Analysis shows that the topography is the final topography with countless hit and the projectile deformation may be produced, so the larger experimental results than the simulation values should be normal.

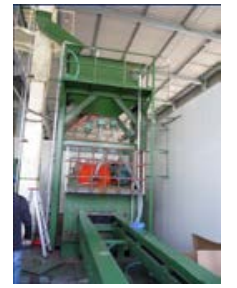

Fig.10 shot blasting equipment

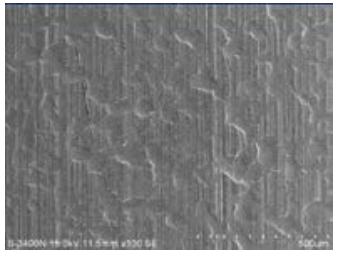

(a) original sample

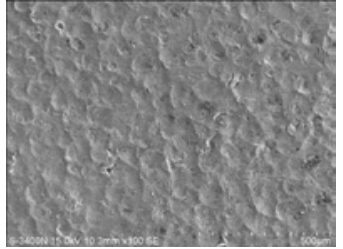

(b) $0.2 \mathrm{~mm}$ sample

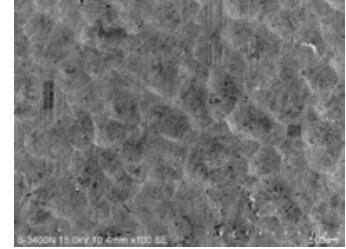

(c) $0.3 \mathrm{~mm}$ sample

Fig.11 Strip steel surface topography

We also make a study about dry and wet shot blasting effect, which is shown in figure 12 . We can find that wet shot blasting makes the surface more uniform and surface scratch decreased obviously.

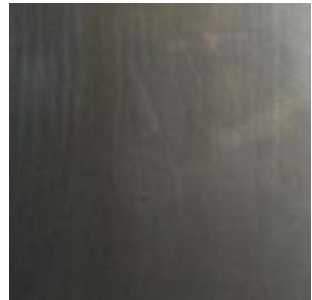

(a) dry shot blasting

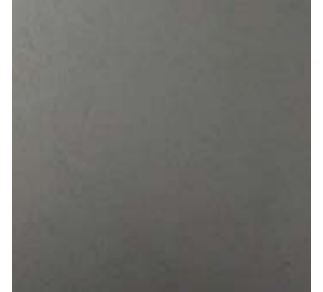

(b) wet shot blasting

Fig.12 Diagram of strip steel surface

\section{Summary}

We propose a new process of wet shot blasting according to a series of problems existing in the conventional shot blasting equipment, environmental pollution and staff health hazards.

The analysis of dry and wet shot blasting finite element simulation shows that wet shot blasting can effectively reduce the surface stress under the condition of ensuring the strip steel surface strain.

Compared with dry shot blasting, because of the existence of water layer, the effect of wet shot blasting is more uniform and almost no scratches.

The experiments shows that wet shot blasting process can replace pickling process and satisfy the demands of strip steel surface treatment.

\section{References}

[1]Lei Zhao. Protection and treatment of acid mist from carbon steel pickling line. Metallurgical Equipment Management and Maintenance.29(2011) p.48-49.

[2] Yubo Liu. Overview of surface treatment process. Beijing: China Metrology Press, 1996.

[3]Pazos L, Corengia P, Svoboda H. Effect of surface treatments on the fatigue life of titanium for biomedical applications. J Mech Behav Biomed Mater.6(2010) 416.

[4]Minsi Qi, Shoujun Liu, Qi Zhao et al.. Simulation analysis of new type landing cushion airbag based on ANSYS/LS-DYNA. Packaging Engineering.11(2014) p.13-17.

[5]YuKui Gao, Mei Yao, Jinkui Li. An analysis of residual stress fields caused by shot peening. Metallurgical and Materials Transactions A.33(2002) p.1775-1778.

[6]Shengwu Wang, Xiuhua Shi , Yonghu Wang et al.. Simulation of stiffened-plate water-entry impact based on ANSYS/LS-DYNA. Computer Measurement \& Control.11(2014) p.13-17.

[7]Al-Hassani S T S. An engineering approach to shot peening mechanics. Proceeding of Second International Conference on Shot Peening, Chicago. 1984.

[8]Mao Liu. Calculation method of elastic plastic rock fall impact force correction based on hertz contact theory. The Chinese Journal of Geological Hazard and Control.23(2012) p.21-27. 